Biological Science", sera fill a gap in the earlier edition.

The present work certainly marks a great advance on its predecessor; but if it is to develop into a standard work, which may well be, its opening chapter should be rewritten, and more attention paid to detail. In several places the text has been corrected or improved, but other opportunities of doing this have not been taken, notably, the more important of those laxities indicated in a review of the first edition (NATURE 133, 665; 1934). S. J. L.

\section{Philosophy and Psychology}

\section{The Origins of Love and Hate}

By Dr. Ian D. Suttie. Pp. xvi+275. (London : Kegan Paul and Co., Ltd., 1935.) 10s. 6d. net.

Tre late Dr. Suttie may be said to have belonged to the 'eclectic' school of English medical psychologists who, influenced by the teaching of pioneers like Freud, have nevertheless never followed slavishly his metapsychology or bound themselves strictly to his psychotherapeutic technique. Indeed, from the outset Suttie questioned the strict psychoanalytic theory on both logical and biological grounds, and later came to reject its basic explanatory concepts for clinical reasons as well. "The Origins of Love and Hate", however, is not a mere criticism of Freudian theory. It offers an alternative account of the underlying psychical determinants of culture and character (including those of the psychopathological manifestations of the latter) as a constructive contribution to general and abnormal psychology.

The main points on which Suttie differs radically from Freud are his insistence upon the role of the mother rather than the father in the mental development of the child, the substitution of love (in the sense of tender emotion) for libido (in the sexual sense) and for the primal hatred involved in the œdipus situation, and the tracing back of neurotic disorders to their root cause in disturbances of the mother-child relation.

The book will provoke discussion and criticism as indicating a new orientation in genetic psychology.

\section{The World of Colour}

By Dr. David Katz. Translated from the German by Dr. R. B. MacLeod and Dr. C. W. Fox. Pp. xvi +300 . (London: Kegan Paul and Co., Ltd., 1935.) 15s. net.

"The World of Colour" deals with colour perception from the purely psychological, as distinguished from the physiological, point of view ; and, on the basis of experimental work, much of which is highly original in character, offers new solutions of problems of great theoretical and practical interest. Among these the most outstanding are those of the illumination of empty space, the differences of the appearance of colours according to their contexts, and the apparent constancy of colour in varying conditions of lighting. The problem of sensory constancy comprises a series of questions having to do with the stability of perception in general ; and, in the particular case of colours, Katz shows that the way in which we see these in different illuminations approximates in all cases to the 'genuine' colour, which is apprehended in the particular illumination that best reveals the microstructure of the illuminated surface.

While the experimental and theoretical parts of the work will be of the greatest interest to psychologists (incidentally also to physicists, physiologists and even philosophers), the application of the theories made to arts and crafts such as architecture, painting, photography, illuminating technique and the like, will prove to be of no less practical value to the artist and craftsman.

The Attitude of Voltaire to Magic and the Sciences By Dr. Margaret S. Libby. (Studies in History, Economics and Public Law, Edited by the Faculty of Political Science of Columbia University, No. 408.) Pp. 299. (New York : Columbia University Press; London : P. S. King and Son, Ltd., 1935.) 16s. 10d. Is this work, which represents a large amount of research, the originality of Voltaire in the field of the various sciences is rightly shown to be overestimated, though for his skill and importance as a popular exponent of the new scientific ideas, he retains full credit. The views of Voltaire are shown here against a background of the scientific developments of his time. Historians of science and philosophy will thus find in this work ample material for consideration and study. It would remain to be shown, for example, what are the detailed relations between the religious philosophy and the history of science in the eighteenth century.

\section{Philosophy and the Concepts of Modern Science}

By Prof. Oliver L. Reiser. Pp. xvii +323. (New York: The Macmillan Co., 1935.) 15s. net.

THE conclusions of the sciences, often used uncritically, help the author to build up a rather peculiar vision of the universe. Pleading for a revival of anthropomorphism and for a religion of humanism, he lets his mind roam from a justification of a modified emergent evolutionism to that of a generalised sun worship, the gap between the two being bridged by a novel conception of light as the link between logic and physics, mind and brain, the physical and the spiritual. The book, though very readable and interesting, is one link in that extraordinary chain of American works which points to the imminent birth of a now Western wisdom the esoteric meaning of which is understandable, at least at present, to a selected few.

T. G.

\section{The Book of the It :}

Psychoanalytic Letters to a Friend. By Dr. Georg Groddeck. Pp. 301. (London: The C. W. Daniel Co., 1935.) 10s. 6d. net. (Supplied to medical and psychological readers only.)

THIs book consists of letters written by Dr. G. Groddeck to a friend. They are all on a psychoan. alytic basis and consist of advice on a variety of matters relating to sex, family life, ete. To those readers who are acquainted with the psychology of sex and its many and varied manifestations in every- 